
SciDioc

International Journal of Clinical \& Experimental Otolaryngology (IJCEO)

ISSN 2572-732X

\title{
A Comparative Evaluation of Audiological and Graft Uptake Results of Reinforced Sliced Conchal Cartilage Versus Temporalis Muscle Fascia Graft In Type I Tympanoplasty
}

Research Article

Singh $\mathrm{SP}^{1^{*}}$, Nagi $\mathrm{RS}^{2}$, Singh $\mathrm{J}^{3}$

${ }^{1}$ ENT Specialist, Swift Hospital, Amritsar, Punjab, India.

${ }^{2}$ Assistant Professor, Department of ENT \& Head Neck Surgery, GMC, Amritsar, Punjab, India.

${ }^{3}$ Professor, Department of ENT \& Head Neck Surgery, GMC, Amritsar, Punjab, India.

Abstract

Aim: The present study aims to evaluate graft uptake rates and audiological results of type I tympanoplasty using sliced conchal cartilage reinforced with temporalis muscle fascia versus temporalis muscle fascia graft.

Material \& Methods: A retrospective study involving a total of 40 patients presenting with dry central perforation with intact and mobile ossicular chain and conductive type of hearing loss, visiting ENT outpatient department of Government Medical College, Amritsar were included in the study. These were randomly divided into two groups of twenty patients each with Group I patients undergoing Type I tympanoplasty with temporalis muscle fascia and Group II patients with sliced conchal cartilage as graft reinforced with temporalis fascia. A pure-tone audiometry was done within 1 week prior to surgery and at 3 months postoperatively to evaluate hearing status.

Results: Graft take up rate in Group I was $85 \%$ while Group II patients had a take up rate of $95 \%(\mathrm{P}<0.01)$. The mean percentage improvement in pre-op pure tone average (PTA) and post-op PTA values in Group I and II was 14.91 (SD \pm 9.741) and $14.48(\mathrm{SD} \pm 9.366)$ respectively $(\mathrm{p}>0.05)$.

Conclusions: Sliced conchal cartilage reinforced with temporalis fascia is a reliable technique for tympanoplasty, especially in large perforations with better graft uptake rates compared to temporalis fascia without affecting audiometric results.

Keywords: Type I Tympanoplasty; Temporalis Fascia; Reinforced Sliced Conchal Cartilage; Pure-Tone Audiomerty (PTA).

\section{Introduction}

The goal of tympanoplasty is to reconstruct the tympanic membrane and the sound-conducting mechanism in a long-lasting way [1]. Since the introduction of this procedure in the $1950 \mathrm{~s}$ by Zoellner [1, 2] and Wullstein [1,3] numerous graft materials and placement techniques have been described to reconstruct the tympanic membrane [4].

Temporalis fascia is the current gold standard graft material for tympanoplasty [5]. Cartilage has been successfully used in middle ear procedures for 40 years, and has been shown to be well tolerated with minimal resorption over time [6]. Initially used for ossicular chain reconstruction, cartilage is now used for a wide range of procedures. Cartilage-perichondrium grafts are frequently the material of choice for reconstruction of the atelectatic tympanic membrane and recurrent perforations. However, this tissue can receive its nutrition by diffusion, and it is easy to work with because it is pliable and can resist deformation from pressure variations. The major advantage of cartilage-perichondrium composite grafts is their stiffness and bradytrophic metabolism [7]. This study was performed to compare the results of graft up-take and audiological outcomes using a $0.5 \mathrm{~mm}$ thick sliced conchal cartilage reinforced by temporalis muscle fascia with temporalis muscle fascia graft alone in type I tympanoplasty.

\section{Aims And Objectives}

1. To evaluate and compare perforation closure rates and hearing results of type I tympanoplasty using sliced conchal cartilage

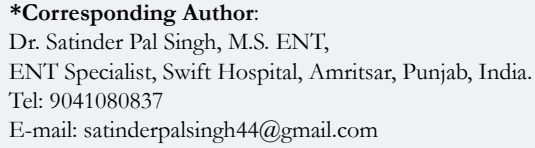

Citation: Singh SP, Nagi RS, Singh J. A Comparative Evaluation of Audiological and Graft Uptake Results of Reinforced Sliced Conchal Cartilage Versus Temporalis Muscle Fascia Graft In Type I Tympanoplasty. Int J Clin Exp Otolaryngol. 2018;4(1):96-100. doi: http://dx.doi.org/10.19070/2572-732X-1800017 
reinforced with temporalis muscle fascia and temporalis muscle fascia alone.

\section{Material And Methods}

A retrospective study involving a total of 40 patients presenting with dry central perforation with intact and mobile ossicular chain and conductive type of hearing loss, visiting ENT outpatient department of Government Medical College, Amritsar were included in the study. These were randomly divided into two groups of twenty patients each with Group I patients undergoing Type I tympanoplasty with temporalis muscle fascia and Group II patients with sliced conchal cartilage as graft reinforced with temporalis fascia. A pure-tone audiometry was done within 1 week prior to surgery and at 3 months postoperatively to evaluate hearing status.

\section{Inclusion Criteria}

1. Dry Central perforation for more than a month with remnant of pars tensa, all around.

2. Intact and mobile ossicular chain

3. Pure, conductive type of hearing loss

\section{Exclusion Criteria}

1. Ear discharge within last month prior to surgery.

2. Possibility of cholesteatoma.

3. Presence of granular myringitis.

4. Revision tympanoplasties.

5. Except ear disease no other disease condition which could affect the result of the study.

Brief details of surgical procedure to be followed:- Under standard aseptic conditions the patient will be appropriately draped. The post-auricular area and external auditory canal will be infiltrated with $1 \%$ xylocaine with 1:100000 adrenaline. In Group I patients temporalis fascia graft will be harvested through the post-auricular incision. In patients of Group II both conchal cartilage graft and temporalis fascia graft will be harvested through the postauricular incision. The cartilage graft so obtained will be thinned with the help of a precise cartilage splitter.

Ossicular mobility and continuity will be assessed. The handle of malleus will be denuded. In patients of Group I temporalis muscle fascial graft will be placed by underlay technique. In Group II patients the sliced cartilage perichondrium composite graft of $0.5 \mathrm{~mm}$ thickness will be placed by underlay technique in a meticulous manner after filling the middle ear with gel foam (Figure 1 and 2). A V-shaped notch was removed from the cartilage shield to accommodate the malleus handle temporalis fascia will be placed lateral to the sliced conchal cartilage by underlay technique.

Antibiotics will be continued for two weeks and antihistaminics for three weeks. At the end of follow-up period on $90^{\text {th }}$ postoperative day the external auditory canal will be cleaned and status of the tympanic membrane will be examined to look for healing/ non-healing of the perforation. Pure-tone audiometry will also be performed to evaluate air-bone gap closure.

\section{Results}

A total number of 40 patients underwent type I tympanoplasty over the study period. Most of the patients were from age group of 18 to 45 years with mean age of patients in Group I was 29.30 \pm 6.46 years while in Group II it was $27.05 \pm 10.44$ years (Table no. 1). In Group I the patients were equally divided based on their gender. However in Group II 55\% were female while 45\% were male. The most common symptom was hearing in the affected ear $87.5 \%$, all the patients were heaving conductive hearing loss with $57.5 \%$ patients having mild, $30 \%$ having moderate and $12.5 \%$ had hearing within normal limits. On otoscopy subtotal perforation was present in $20 \%$ of patients, $12.5 \%$ big central, $37.5 \%$ medium sized and 30\% small central peroration.

Graft uptake rate in Group I was 85\% while Group II patients had a uptake rate of $95 \%(\mathrm{P}<0.001)$. Loss of graft or partial uptake was there in about $20 \%$ of the patients. The mean percentage improvement in pre-op pure tone average (PTA) and post-op PTA values in Group I and II was $14.91(\mathrm{SD} \pm 9.741)$ and 14.48 $(\mathrm{SD} \pm 9.366)$ respectively $(\mathrm{p}>0.05)$ (Table no. $\mathrm{II})$.

\section{Discussion}

The term tympanoplasty was coined by Wullstein in 1953, and is defined as any operation where the tympanic membrane is reconstructed with or without reconstruction of the ossicular chain [3]. The repair of the tympanic membrane has been attempted with large variety of synthetic, Homologous, Autogenous tissues, Temporalis fascia, Areolar tissue, Perichondrium are used most commonly today [4]. Temporalis fascia is the current gold standard graft material. Cartilage was first introduced in middle

Figure 1 and 2. Conchal Cartilage Slicing With Cartilage Slicer.

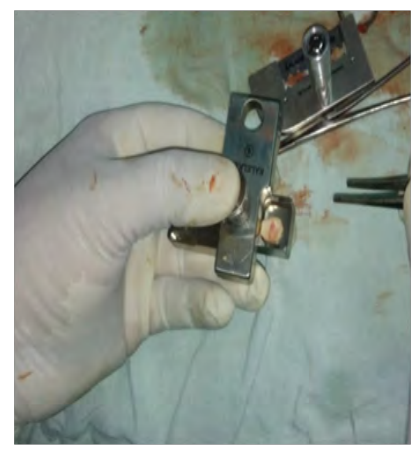

Figure 1

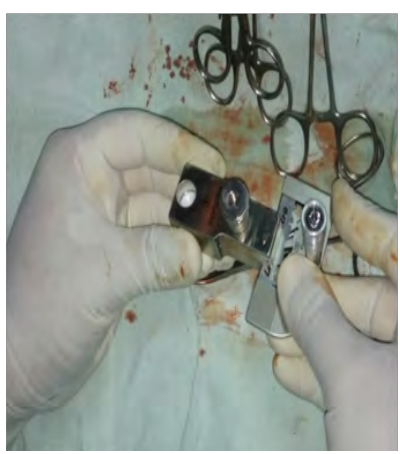

Figure 2 
Table 1. Age Wise Distribution of Patients.

\begin{tabular}{|c|c|c|c|}
\hline Age in years & Group I & Group Il & Total \\
\hline $15-25$ & $4(20 \%)$ & $13(65 \%)$ & $17(42.5 \%)$ \\
\hline $26-35$ & $12(60 \%)$ & $2(10 \%)$ & $14(32.5 \%)$ \\
\hline $36-45$ & $4(20 \%)$ & $5(25 \%)$ & $9(22.5 \%)$ \\
\hline Total & $20(100 \%)$ & $20(100 \%)$ & $40(100 \%)$ \\
\hline $\mathrm{n}=40$ & $\mathrm{p}=>0.05$
\end{tabular}

Table 2. Audiological Outcome $90^{\text {th }}$ PTA Gain.

\begin{tabular}{|c|c|c|c|}
\hline Group & Mean Pre-op PTA & Mean Post-op PTA & Mean Percentage Change \\
\hline Group I & $39.07(\mathrm{SD} \pm 12.301)$ & $24.16(\mathrm{SD} \pm 9.357)$ & $14.916(\mathrm{SD} \pm 9.741)$ \\
\hline Group Il & $33.93(\mathrm{SD} \pm 10.235)$ & $19.44(\mathrm{SD} \pm 7.655)$ & $14.485(\mathrm{SD} \pm 9.366)$ \\
\hline
\end{tabular}

$\mathrm{n}=40$

$\mathrm{p}>0.05$

ear surgery in 1959 by Utech [8, 9]. Cartilage has been successfully used in middle ear procedures for 40 years, and has been shown to be well tolerated with minimal resorption over time [5]. Initially used for ossicular chain reconstruction, cartilage is now used for a wide range of procedures. Cartilage-perichondrium grafts are frequently the material of choice for reconstruction of the atelectatic tympanic membrane and recurrent perforations. The technique was then promoted by Prof. Heermann J. from Essen, Germany, who used "the cartilage palisade technique" for the reconstruction of the tympanic membrane and the auditory canal wall $[10,11]$ Perichondrium and cartilage share with fascia the quality of being mesenchymal tissue, but they are thicker and stiffer. They mechanically reduce the vibratory pattern of the tympanic membrane, contributing to some impairment in functional results, especially in the higher tones [11] Overbosch in 1971 was first to describe a microslice technique to improve the acoustic properties of the reconstructed tympanic membrane. He cut the cartilage by a dermatome into plates with thickness of $0.2-1 \mathrm{~mm}[12]$.

An optimal cartilage thickness should be a compromise between good acoustic properties and sufficient mechanical stability against static middle-ear pressure changes. In experimental study by Zahnert, it is suggested that reducing the thickness of the cartilage slices to less than 500 micrometers gives acoustic properties similar to the tympanic membrane. The thicker disk has higher stiffness than tympanic membrane. In normal/partially ventilated middle ear, thickness up to $0.5 \mathrm{~mm}$ gives sufficient mechanical stability and low acoustic transfer loss, but in cases of atelectatic ears due to chronic Eustachian tube dysfunction, disk $>0.5 \mathrm{~mm}$ thickness should provide a more stable reconstruction. [13].

This study was performed to compare the results of graft uptake and audiological outcomes using a $0.5 \mathrm{~mm}$ thick sliced conchal cartilage reinforced by temporalis muscle fasica verses temporalis muscle fascia graft alone in type I tympanoplasty.

\section{Graft Uptake Results}

Graft uptake rate in Group I was 85\% while Group II patients had a uptake rate of $95 \%(\mathrm{P}<0.001)$. Loss of graft or partial uptake was there in about $20 \%$ of the patients (Table no. III).
Thus, the perforation closure rate in patients belonging to group II was better than those in Group I.

In a study by Kazikdas KC on Palisade cartilage tympanoplasty, graft take was achieved in 22 patients (95.7\%) in palisade cartilage group and in 21 patients $(75 \%)$ in temporalis fascia group $(\mathrm{P}=0.059)$ [17] Zahnert et al., 24, cartilage slices $<500$ $\mu \mathrm{m}$ thick are similar to the tympanic membrane in terms of their acoustic properties. They reported that when the large tympanic membrane defects are reconstructed with thick pieces of cartilage, transmission losses occurred at lower frequencies. The thicker disk has higher stiffness than tympanic membrane [13] Khan et al., concluded that reinforcement of temporalis fascia with sliced tragal cartilage is a reliable technique for tympanoplasty, especially in large perforations. In this study the authors found that the technique greatly increased the rate of tympanic membrane closure without affecting audiometric results [19].

Advantages of Reinforced Sliced Conchal Cartilage Graft:

1. Minimal displacement (lateralization or medialisation) of the graft as cartilage disc snugly juts out through the perforation.

2. Remnant tympanic membrane is strengthened by the temporalis muscle fasica.

3. Reduced rate of residual perforation and recurrent perforation 4. In contrast to full thickness island graft, the sliced island is of acoustic benefit.

5. Any site and size of the perforation can be reconstructed effectively by altering the size of the cartilage disc in the middle of the island.

6. The curling effect of the sliced cartilage is offset by fashioning as an island.

7. Placement and manipulation of the island graft is simpler and easier.

8. Benefit and prevent the retraction of the grafted fascia in myringoplasty.

\section{Audiological Outcome}

The mean PTA in Group I was 39.07(SD \pm 12.301) and postop pure tone average was $24.16(\mathrm{SD} \pm 9.357)$. The mean pre-op pure tone average (PTA) in study group Group II was 33.93(SD \pm 10.235 ) and post-op PTA was 19.44(SD \pm 7.655) (Table no. 
Table 3. Graft Uptake Results.

\begin{tabular}{|c|c|c|}
\hline NAMES & GRAFT MATERIALS & SUCCESS RATE \\
\hline \multirow{2}{*}{ OUR STUDY } & Temporalis muscle Fascia (GROUP I) & $85 \%$ \\
\cline { 2 - 3 } & Reinforced sliced conchal cartilage (GROUP II) & $95 \%$ \\
\hline $\begin{array}{c}\text { Iacovou E, Vlastarakos } \\
\text { PV et al., [14] }\end{array}$ & Cartilage & $92.40 \%$ \\
\cline { 2 - 3 } Tek A ${ }^{1}$, Karaman M., [15] & Temporalis Fascia & $84.30 \%$ \\
\cline { 2 - 3 } & Cartilage reinforcement in revision cases & $100 \%$ \\
\hline \multirow{2}{*}{ Khan, Parab [16] } & Temporalis Fascia in revision cases & $66 \%$ \\
\cline { 2 - 3 } & Sliced tragal cartilage & $97.20 \%$ \\
\hline \multirow{2}{*}{ Kazikdas KC [17] } & Temporalis fascia & $87.42 \%$ \\
\cline { 2 - 3 } & Palisade cartilage & $95.70 \%$ \\
\hline \multirow{2}{*}{ Yu et al., [18] } & Temporalis Fascia & $75 \%$ \\
\cline { 2 - 3 } & Cartilage & $92.40 \%$ \\
\hline
\end{tabular}

Figure 3. Pre and Post-Operative degree of hearing loss in Group I and II.

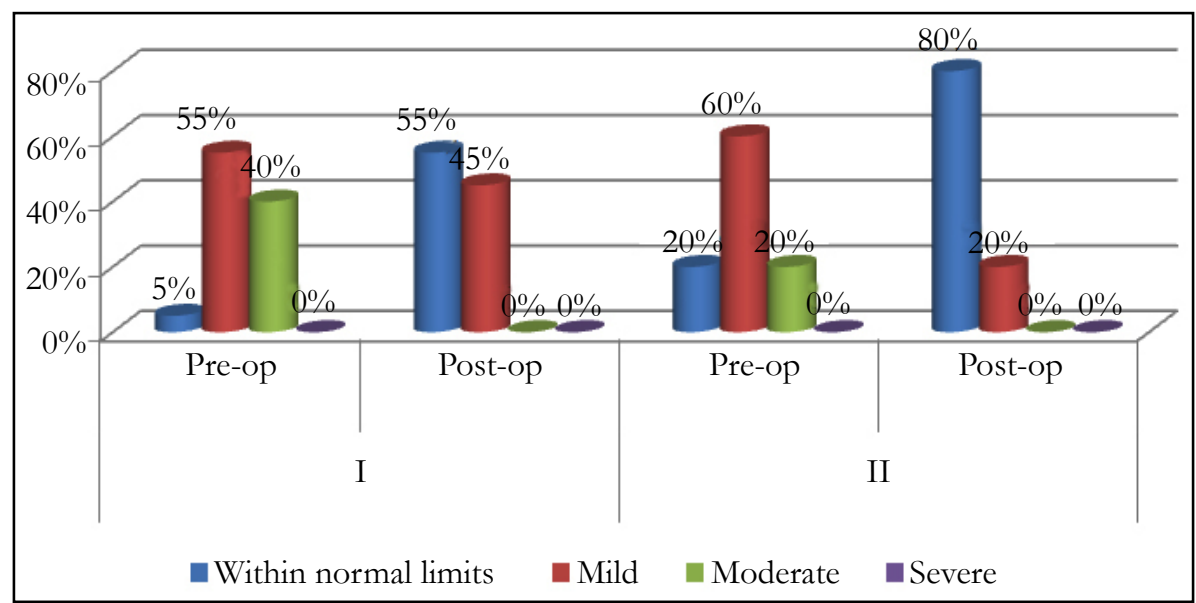

II). The mean percentage change in pre-op and post-op values in Group I and II was 14.91 (SD \pm 9.741) and 14.48 (SD \pm 9.366) respectively (Table no. IV). Concerning the audiological parameters, the difference between preoperative and postoperative hearing levels was statistically significant $(\mathrm{P}<0.001)$ (Figure no. 3). Thus there was no statistically significantly improvement in Air Bone gap in Group I as compared to Group II.

Aidonis Loannis, Robertson et al., reported their experience with Cartilage Shied Tympanoplasty Graft uptake was in 98.4\% with no postoperative complication. The average preoperative and postoperative pure tone average air bone gap were $32.4+/-14.1$ $\mathrm{dB}$ and $24+/-13.7 \mathrm{~dB}$ respectively $(\mathrm{p}>0.05)$ [20]. Sanjana V. Nemade et al., studied 90 patients were included who underwent type one tympanoplasty. 30 cases were included in Group A in which temporalis fascia was used. 30 cases were included in Group B in which full thickness tragal cartilage $(1 \mathrm{~mm})$ was used and 30 cases were included in Group $C$ in which partial thickness $(0.5 \mathrm{~mm})$ tragal cartilage was used. The average Air-Bone gap closure achieved in Group A was $27.4 \mathrm{~dB}$; in Group B was $17.5 \mathrm{~dB}$ while in Group C it was $26.8 \mathrm{~dB}$. For Group A and C, value was statistically no significant difference was noted in Air-Bone gap closure of two groups [21].

Ozbec C et al., [22] studied involving type I tympanoplasty it was concluded that tympanoplasty with the palisade cartilage technique resulted in a significantly higher graft acceptance rate $(100 \%)$ than with the fascia technique $(70.2 \% ; \mathrm{p}=0.008)$. Speech reception threshold levels, pure-tone average, and airbone gaps improved significantly with surgery in both the palisade and fascia groups ( $p<0.001)$. Comparison of audiologic results between the groups did not reveal any statistically significant difference $(p>0.05)$ [15]. Khan, Parab et al., evaluate anatomical and audiological results after primary cartilage tympanoplasty using sliced tragal cartilage reinforced with temporalis fascia in large perforations, the pre-operative $\mathrm{AB}$ gaps was $32.464+5.0220 \mathrm{~dB}$ and post-operative $\mathrm{AB}$ gap was $9.2131+3.2823 \mathrm{~dB}$ at 6 months, $\mathrm{AB}$ gap was $10.3246+4.5427 \mathrm{~dB}$ at one year, and $9.6429+2.6557$ $\mathrm{dB}$ at 2 years of follow up. The pre-operative and the postoperative difference in the $\mathrm{AB}$ gap were statistically significant $(\mathrm{p}$ $<0.05)[19]$.

\section{Conclusion}

Sliced conchal cartilage reinforced with temporalis fascia is a reliable technique for tympanoplasty, with better graft uptake rates compared to temporalis fascia without affecting audiometric results. 


\section{References}

[1]. Albirmawy OA. Comparison between cartilage-perichondrium composite 'ring' graft and temporalis fascia in type one tympanoplasty in children. J Laryngol Otol. 2010 Sep;124(9):967-74. doi: 10.1017/S0022215110000885. Epub 2010 Apr 20. PubMed PMID: 20403227.

[2]. Zollner F. The principles of plastic surgery of the sound-conducting apparatus. J Laryngol Otol. 1955 Oct;69(10):637-52. PubMed PMID: 13263770.

[3]. Wullstein HL. Functional operations in the middle ear with split-thickness skin graft. Arch Otorhinolaryngol. 1953;161:422-35.

[4]. Rizer FM. Overlay versus underlay tympanoplasty. Part I: historical review of the literature. Laryngoscope. 1997 Dec;107(12 Pt 2):1-25. PubMed PMID: 9395343.

[5]. Yung MW. Myringoplasty: hearing gain in relation to perforation site. J Laryngol Otol. 1983 Jan;97(1):11-7. PubMed PMID: 6822768.

[6]. Kerr AG, Byrne JE, Smyth GD. Cartilage homografts in the middle ear: a long-term histological study. J Laryngol Otol. 1973 Dec;87(12):1193-9. PubMed PMID: 4760609.

[7]. Tos M. Cartilage tympanoplasty methods: proposal of a classification. Otolaryngol Head Neck Surg. 2008 Dec;139(6):747-58. PubMed PMID: 19041498 .

[8]. Utech H. On the diagnostic and therapeutic possibilities of tympanotomy in case of conductive disorders. Laryngol rhinol. 1959; 38: 212-21.

[9]. Heermann J. Auricular cartilage palisade tympano-, epitympano-, antrumand mastoid-plastics. Clin Otolaryngol Allied Sci. 1978 Nov;3(4):443-6. PubMed PMID: 743792.

[10]. Heermann J. Autograft tragal and conchal palisade cartilage and perichondrium in tympanomastoid reconstruction. Ear Nose Throat J. 1992 Aug;71(8):344-9. PubMed PMID: 1396182.

[11]. Yung M. Cartilage tympanoplasty: literature review. J Laryngol Otol. 2008 Jul;122(7):663-72. PubMed PMID: 18312709.

[12]. Zahnert T, Hüttenbrink KB, Mürbe D, Bornitz M. Experimental investigations of the use of cartilage in tympanic membrane reconstruction. Am J
Otol. 2000 May;21(3):322-8. PubMed PMID: 10821543.

[13]. Overbosch HC. Homograft myringoplasty with micro-sliced septal cartilage. Pract Otorhinolaryngol (Basel). 1971;33(5):356-7. PubMed PMID: 5159317.

[14]. Iacovou E, Vlastarakos PV, Papacharalampous G, Kyrodimos E, Nikolopoulos TP. Is cartilage better than temporalis muscle fascia in type I tympanoplasty? Implications for current surgical practice. Eur Arch Otorhinolaryngol. 2013 Nov;270(11):2803-13. PubMed PMID: 23321796.

[15]. Tek A, Karaman M, Uslu C, et al. Audiological and graft take results of cartilage reinforcement tympanoplasty (a new technique) versus fascia. Eur Arch Otorhinolaryngol. 2012 Apr;269(4):1117-26. PubMed PMID: 21968630.

[16]. Khan MM, Parab SR. Comparative study of sliced tragal cartilage and temporalis fascia in type I tympanoplasty. J Laryngol Otol. 2015 Jan;129(1):1622. PubMed PMID: 25602596.

[17]. Kazikdas KC, Onal K, Boyraz I, Karabulut E. Palisade cartilage tympanoplasty for management of subtotal perforations: a comparison with the temporalis fascia technique. Eur Arch Otorhinolaryngol. 2007 Sep;264(9):9859. PubMed PMID: 17401572.

[18]. Yu L, Han C, Yu H, Yu D. Auricular cartilage palisade technique for repairing tympanic membrane perforation. Zhonghua Er Bi Yan Hou Ke Za Zhi. 2001 Jun;36(3):166-8. PubMed PMID: 12761914.

[19]. Khan MM, Parab SR. Reinforcement of sliced tragal cartilage perichondrium composite graft with temporalis fascia in type I tympanoplasty: our techniques and results. J Rhinol-Otol. 2013;1(1):57-62.

[20]. Aidonis I, Robertson TC, Sismanis A. Cartilage shield tympanoplasty: a reliable technique. Otol Neurotol. 2005 Sep;26(5):838-41. PubMed PMID: 16151325.

[21]. Dabholkar SV. "Healing and hearing results of temporalis fascia graft Vs cartilage graft (Full thickness and half thickness) in type I tympanoplasty. J Otolaryngol . 2014 May 16;4(3):1-20.

[22]. Ozbek C, Ciftci O, Tuna EE, Yazkan O, Ozdem C. A comparison of cartilage palisades and fascia in type 1 tympanoplasty in children: anatomic and functional results. Otol Neurotol. 2008 Aug;29(5):679-83. PubMed PMID: 18580702 . 